\title{
ESTÁGIOS DE ENVOLVIMENTO CIENTÍFICO E TECNOLÓGICO NAS MICRORREGIÕES DE MINAS GERAIS
}

\author{
Maria Isabel Batista D G Baptista (CEDEPLAR/UFMG) \\ Jonas da Silva Henrique (CEDEPLAR/UFMG) \\ Pedro Mário de Freitas (CODEMIG)
}

\begin{abstract}
RESUMO: O presente artigo classifica e analisa os diferentes estágios do envolvimento científico e tecnológico em que se encontram as microrregiões de Minas Gerais. A partir da reunião das proxies mais comumente encontradas na literatura, são avaliadas e mensuradas as capacidades estruturais que contemplam diretamente o sistema regional de inovação, bem como os seus determinais locacionais. Para tanto, utilizou-se do ferramental analítico conhecido como análise fatorial dos componentes principais. Este método possibilita a construção de um indicador local (IECT) e facilita a interpretação e localização dos resultados. Os efeitos do envolvimento científico e tecnológico nas microrregiões de Minas Gerais foram formaram dois grandes agrupamentos, sendo o principal; a microrregião de Belo Horizonte e seu entorno metropolitano; e o agrupamento secundário localizado na região do triângulo mineiro.
\end{abstract}

ABSTARCT: This article classifies and analyzes the different stages of the scientific and technological involvement in the microregions (group of municipalities) of Minas Gerais. The structural capacities that directly contemplate the regional innovation system and as its locational determinants are evaluated and measured joining the most commonly applied proxies in the literature. The analytical tool known as the factorial analysis of the main components has been used. This method allows creating a local indicator (IECT) and facilitates interpretation and localization of the results. The effects of the scientific and technological involvement in the microregions of Minas Gerais formed two large groupings, the main one being; the microregion of Belo Horizonte and its metropolitan environment; and the secondary cluster the Triângulo Mineiro region.

Palavras-chave: Inovação, Desigualdade Espacial, Estrutura Tecnológica

Área ABEIN: 1 - Indústria e competitividade 1.4 Padrões de especialização produtiva e desenvolvimento Classificação JEL: R12, R58, O18 


\section{INTRODUÇÃO}

Utilizando referencial neoschumpeteriano, o presente trabalho busca compreender e analisar o sistema regional de inovação de Minas Gerais através da mensuração da concentração e da maturidade das estruturas de apoio a atividades inovativas em seu território. A redução das desigualdades regionais, por intermédio um sistema de cooperação e interação é o caminho apontado pela literatura para a superação do subdesenvolvimento, uma vez que se provoca um aumento da competitividade de uma economia no mercado mundial, partindo da indução do fomento das atividades tecnológicas locais.

Tomando por pressuposto que, o desenvolvimento não ocorre da mesma maneira em diferentes pontos no tempo/espaço, é necessário compreender a dinâmica econômica local, que no caso deste trabalho a referência está no discernimento do envolvimento científico e tecnológico que ocorre no estado, perante aos que teriam edificações mais avançadas e, por sua vez, maior produtividade interna, frente às regiões que possuem composições mais vulneráveis ou incipientes na ciência e tecnologia.

Uma vez que as regiões detentoras de um sistema de inovação, ciência e tecnologia, mais adiantado, são aquelas que possuem maior nível de retornos da sua produção, consequentemente, renda mais elevada, além de tendências de diversificação na estrutura produtiva, maior estrutura para o desenvolvimento científico, bem como a qualificação local de profissionais de alto nível educacional, bem como a sua absorção do mercado de trabalho regional. Em vista destas evidências, esta pesquisa tem por objetivo esmiuçar quais os estágios de envolvimento com a ciência e tecnologia que se encontram as microrregiões de Minas Gerais, tendo como meio de distinção as desigualdades concentradas entre as sessenta e seis microrregiões do estado, considerando variáveis de cunho demográfico, geográfico, econômico, e social, correlacionando-as para a construção do Índice de Envolvimento Científico e Tecnológico - IECT.

Esse trabalho é divido em três partes além da introdução e da conclusão. Na primeira seção é feita uma revisão da literatura sobre inovação e desenvolvimento econômico, começando por aspectos teóricos relacionados à obra clássica de Schumpeter e chegando finalmente ao conceito de Sistema Regional de Inovação. Em seguida será apresentado o método de análise fatorial, bem como sua aplicação no presente trabalho que analisa as sessenta e seis microrregiões administrativas do estado de Minas Gerais e as variáveis utilizadas. A terceira seção apresenta os resultados obtidos por meio do exercício proposto e busca apresentar uma justificativa baseada na teoria apresentada. 
Schumpeter é considerado o principal autor responsável pela percepção da inovação como motor da dinâmica do sistema econômico capitalista. Em sua obra Teoria do Desenvolvimento Econômico (1911), afirma que as inovações tecnológicas que causam distúrbio no equilíbrio de mercado e são as condutoras do desenvolvimento econômico.

Em sua visão, o desenvolvimento econômico é condicionado pela história e por escolhas de agentes sociais e políticos em conflito, baseado em acumulação de capital, inovação tecnológica e evolução institucional.

Em Capitalismo, Socialismo e Democracia (1942), Schumpeter escreveu que a destruição criativa originada de um processo de inovação se configura como "o fato essencial do capitalismo". A destruição criativa aumenta a taxa de crescimento econômico de longo prazo e renovando o sistema. Por isso, um país que busca o desenvolvimento econômico deve assimilar, transformar e criar novas tecnologias, garantindo sua competitividade nas trocas globais.

A partir da década de 1970, trabalhos de Chris Freeman, Richard Nelson e Nathan Rosenberg trouxeram uma nova compreensão sobre a inovação, que deixou de ser vista como a descoberta de novos princípios técnicos e científicos.

O processo de inovação passou a ser entendido como um conjunto de complexas interações entre agentes nos níveis local, nacional e mundial. É, portanto, um processo de aprendizado derivado de complexas interações entre indivíduos, firmas e outras organizações voltadas à busca de novos conhecimentos (Santos e Caliari, 2012).

Para o processo inovativo, foi reconhecida a importância de redes formais e informais de interação e cooperação, de ligações com fontes externas de informação científica e tecnológica e da integração entre pesquisa e desenvolvimento (P\&D), produção, design e marketing (Szapiro et al, 2017).

\subsection{Externalidades}

Dois tipos de externalidades positivas locais são reconhecidos por exercerem papel importante no processo de criação e disseminação de novos conhecimentos. Por um lado, há externalidades de especialização, que operam quando a estrutura produtiva de uma região é caracterizada pela forte especialização em uma determinada indústria. De outro lado, as externalidades que emergem da diversificação, verificadas em estruturas produtivas complexas e diversificadas.

O principal autor que apontou a importância das economias de especialização foi Marshall (1920). A partir desse trabalho, Arrow (1962) e Romer (1986) formalizaram o modelo que ficou conhecido com MAR (Marshall-Arrow-Romer). Nesse modelo, a especialização tem o importante efeito de estimular a circulação de informações, de ideias e o compartilhamento de conhecimento tácito e codificado por meio de processos de imitação, interação entre os agentes e mobilidade dos trabalhadores. As externalidades de especialização ocorrem somente entre empresas da mesma indústria ou de indústrias correlatas.

Por outro lado, Jacobs (1969) apontou que a diversidade da estrutura produtiva de uma região ou de uma cidade é o principal motor da inovação. As estruturas produtivas diversificadas são conducentes para o intercâmbio de habilidades necessário para a emergência de novos setores e de novas atividades produtivas, uma vez que essas habilidades podem ser recombinadas para a produção de novas mercadorias e o atendimento a novos mercados. Além disso, a existência de uma adequada infraestrutura de transportes e comunicação, a proximidade aos mercados e o acesso privilegiado a serviços especializados são fontes adicionais de externalidades de diversificação, bastantes associadas à urbanização e muitas vezes chamadas de externalidades jacobianas.

Autores neo-schumpeterianos iniciaram uma ampla agenda de pesquisa procurando avançar no entendimento sobre o processo de inovação e seus principais determinantes. Nesse contexto, Nelson e Winter (1977) desenvolveram as bases daquela que, mais tarde, ficou conhecida como teoria evolucionista da inovação, e apresentaram seus elementos centrais de forma um pouco mais sistemática em seu livro clássico de 1982. 
Mais tarde, foram associados elementos da teoria de economia regional à teoria de desenvolvimento de Schumpeter culminando na síntese de Sistemas de Inovação.

\subsection{Sistemas de Inovação}

Em 1988, foi publicada a clássica coletânea Technical Change and Economic Theory (Dosi et al, 1988) que introduziu na literatura acadêmica a ideia de sistemas de inovação. A difusão desse conceito coincide com ao surgimento do novo paradigma das tecnologias de informação.

A instituição do paradigma da economia do conhecimento impôs uma nova dinâmica de concorrência na economia global após a década de 1980, caracterizada por uma crescente valorização das ideias em meio ao processo produtivo. Investimentos em qualificação da mão-de-obra e expansão de centros de pesquisa e desenvolvimento (P\&D) passam a fazer parte da rotina das grandes empresas, que buscam a inovação.

A contribuição de Freeman (1995) para o conceito de sistemas de inovação é paradigmática. Seus argumentos sobre a relação entre crescimento econômico e tecnologia se opõem aos dos neoclássicos por dar ênfase ao papel ativo do Estado na construção de condições para que as empresas inseridas em seu território se engajem no desenvolvimento de tecnologias promissoras (Bittencourt e Cário, 2017).

Freeman define o conceito Sistema Nacional e Inovação (SNI) como rede de instituições dos setores público e privado cujas atividades e interações iniciam, importam, difundem e modificam novas tecnologias.

Nessa percepção, os processos de inovação são marcados por mecanismos de feedback e relações de interação envolvendo ciência, tecnologia, produção, políticas públicas e demanda dos usuários(Szapiro et al, 2017).

A capacidade inovativa de um país ou região é vista, assim, como resultado das relações entre agentes econômicos, políticos e sociais e reflete condições culturais e institucionais próprias. Dito de outra maneira, na abordagem dos Sistemas de Inovação, o processo inovativo é path dependent.

"O Sistema Nacional de Inovação é um sistema aberto, que evolui e complexo que engloba relações internas e externas de organizações, instituições e estruturas socioeconômicas, que determinam a taxa e a direção da inovação e a construção de competências emanadas de processos de aprendizados baseados na ciência e experiência." (Lundvall ,2009)

A abordagem de sistema de inovação se torna um instrumento analítico extremamente importante porque reforça o caráter localizado da geração, assimilação e difusão da inovação, que não é anulado pelo aprofundamento da integração entre as economias nacionais. Não obstante o aumento da importância das relações globais de produção, a tecnologia não pode ser gerada em qualquer local e facilmente difundida para diferentes partes do globo.

$\mathrm{Na}$ abordagem neoschumpeteriana, o processo de inovação é localizado, fundamentalmente social e enraizado culturalmente. Nesse aspecto, destaca-se a importância da influência das instituições que oferecem incentivos ou restrições para a inovação tais como leis, regulações, normas culturais, regras sociais e padrões técnicos.

\subsection{Sistemas Regionais de Inovação}

Os avanços na tecnologia da informação criaram novos padrões de competitividade frente a um modelo globalizado de acumulação de capitais. As capacidades de geração, absorção e difusão de conhecimento passaram a figurar dentre os principais diferenciais para a competitividade no plano internacional. Isso fez com que as vantagens competitivas baseadas no conhecimento e na inovação tecnológica prevalecessem sobre as vantagens baseadas em preços e escala produtiva (Santos e Caliari, 2012). 
Os primeiros trabalhos acadêmicos e os relatórios de políticas utilizando a abordagem de Sistemas de Inovação apresentaram um reconte nacional. A decisão por essa dimensão de análise se explica pela trajetória histórica compartilhada por todos os agentes em uma nação, tais como: arcabouço institucional; sistemas educacionais e de ciência e tecnologia; bases socioculturais, estruturas de capital; quadro político e políticas industrial e de CT\&I nacionais (Szapiro et al, 2017).

Não obstante, é no território compreendido como espaço cognitivo em que ocorrem os processos interativos e cooperativos que levam à inovação e onde se deve centrar a abordagem.

O sucesso de experiências regionais como a do Vale do Silício, nos Estados Unidos, e a dos distritos industriais, da chamada terceira Itália, reascenderam o debate sobre a importância da localidade e de suas peculiaridades para o desenvolvimento produtivo. Vieram à tona as vantagens da aglomeração industrial, como a presença de trabalho qualificado, a interação via cooperação e competição, a imersão local e as economias externas, e seus reflexos sobre a produção de inovações (Asheim, 1995).

O conceito de sistemas regionais de inovação (SRIs) buscou superar uma limitação da teoria do SNIs, a de não levar em conta as peculiaridades regionais. A existência de desequilíbrios regionais é algo persistente principalmente em países subdesenvolvidos e de grandes dimensões como o Brasil. Dessa forma, a opção pela análise do SRI de Minas Gerais nesse trabalho se mostra adequada.

O SRI é composto por relações de cooperação entre agentes da infraestrutura produtiva local que levam a geração e internalização de novos conhecimentos técnico-científicos. Os principais agentes são as empresas inovadoras, instituições criadoras de conhecimento como universidades e centros de pesquisa, instituições voltadas à transferência de tecnologia, instituições de suporte a inovação, e o sistema financeiro.

O grau de maturidade de um SRI pode ser avaliado a partir da intensidade das relações de interações que levam à inovação, do grau de relacionamento dos agentes e a capacidade de aprendizado local. Esse artigo faz essa análise a partir do método de análise fatorial.

A relação entre proximidade geográfica e as possibilidades de compartilhamento de conhecimentos entre agentes parte do pressuposto de que o conhecimento possui dois componentes distintos. O primeiro é o conhecimento codificado, que pode ser transferido entre os agentes por meio de manuais. O segundo é o conhecimento tácito, cujo compartilhamento envolve, necessariamente, interação entre os agentes, o que dificulta a sua transferência a longas distâncias.

O conhecimento tácito está enraizado nos indivíduos e nas rotinas das empresas. Nesse sentido, ele pode ser considerado o principal fator de concentração geográfica de atividades inovativas, porque seu papel central no processo de aprendizado interativo reforça os efeitos positivos da localização, da proximidade geográfica e da concentração espacial dos agentes econômicos (Garcia, 2017).

Lundvall, após analisar os determinantes da inovação, concluiu que o recurso mais estratégico à dinâmica da inovação é o aprendizado que surge da interação entre as pessoas imersas em um ambiente social particular.

$\mathrm{O}$ autor considera o aprendizado por $\mathrm{P} \& \mathrm{D}$ interna (learning by searching),pela interação com centros de pesquisas e universidades (learning from advanced $S \& T$ ), o learning by doing, relacionado a melhorias no ambiente de produção, o learning by using, relacionado a ganhos pelo aprendizado com sistemas mais complexos, e o learning by interacting, relacionado a inovações de produtos surgidas da interação de produtos e usuários (Bittencourt e Cário, 2017).

Deve-se destacar a existência de uma relação reflexiva entre conhecimento tácito e o contexto, uma vez que o conhecimento tácito, ao mesmo tempo, define e é definido pelo contexto social. A aprendizagem interativa e de longo prazo, capaz de transferir conhecimentos tácitos encontraria menos barreiras onde estão presentes afinidades culturais e lingüísticas, por exemplo.

Em verdade, regiões são marcadas por path dependence, demonstrando que a história importa na construção do desenvolvimento, dado que possibilita, no presente, construir a estrutura desejada para o futuro. Assim, há espaço para mudanças nas trajetórias de desenvolvimento regional.

A partir da síntese neoschumpeteriana que sistematizou uma teoria sobre os determinantes regionais da inovação e sua relação com o desenvolvimento econômico, uma análise empírica é feita nesse trabalho para se avaliar o sistema regional de inovação de Minas Gerais. 
Foram utilizados dados que fornecem informações sobre os componentes da estrutura de fomento à inovação tais como qualificação da mão-de-obra, centros de P\&D, redes de interação e cooperação e economias externas de especialização e de diversificação.

\section{METODOLOGIA}

Tendo por base as referências literárias envolvidas neste texto, as informações estatísticas reunidas para as microrregiões do estado de Minas Gerais, Figura 1, foram alinhadas para a utilização da técnica de análise fatorial. O objetivo desta aplicação é construir o Indicador de Envolvimento Científico e Tecnológico (IECT), ressaltando a atual disposição nas regiões mineiras, correlacionando-os com o comportamento médio da estrutura encontrada no estado. Com a utilização do método estatístico multivariado, pode-se verificar o efeito de cada variável disposta no modelo, além de considerar a relação entre as variáveis escolhidas.

\section{Figura 1}

\section{Região de Análise: Microrregiões de Minas Gerais ${ }^{1}$ - BR}

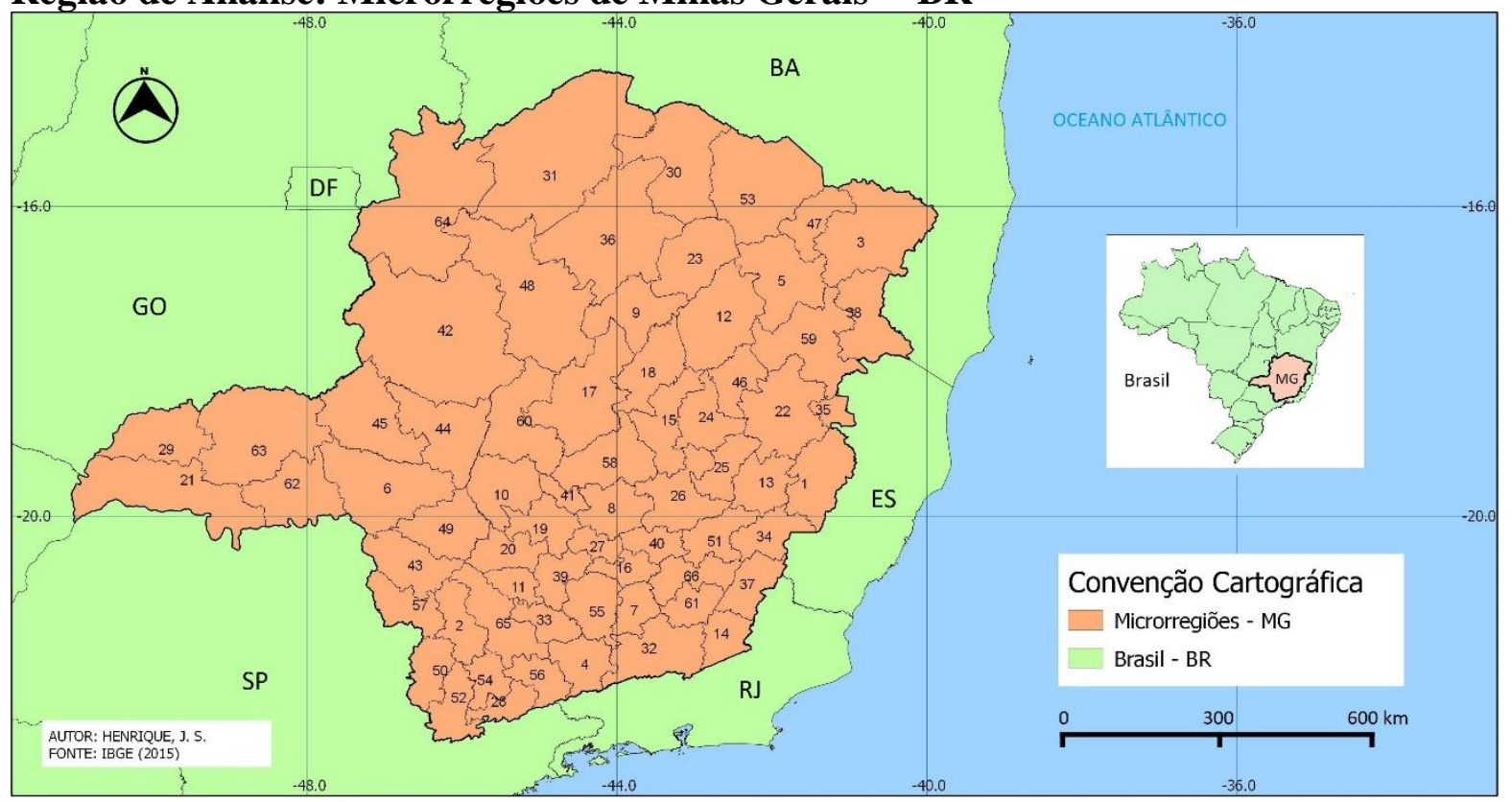

Fonte: IBGE (2010), elaborado pelo autor.

Ao pressupor a inter-relação de todas as variáveis elencadas, torna-se importante a análise do comportamento de todas as variáveis simultaneamente. Assim como nos trabalhos de Perobelli et al (1999), Prates Rodrigues (2002), Froehlich e Neumann (2007), e Eberhardt (2013) e, principalmente, Santos e Caliari (2012), que também fazem uso deste método para dar referência conjunta ao comportamento das variáveis informativas na construção estatística de indicadores de desenvolvimento e distribuição espacial.

${ }^{1}$ Microrregiões referentes - 1- Aimorés; 2 - Alfenas; 3 - Almenara; 4 - Andrelândia; 5 - Araçuaí; 6 - Araxá; 7 Barbacena; 8 - Belo Horizonte; 9 - Bocaiúva; 10 - Bom Despacho; 11- Campo Belo; 12 - Capelinha; 13 - Caratinga; 14 Cataguases; 15 - Conceição do Mato Dentro; 16 - Conselheiro Lafaiete; 17 - Curvelo; 18 - Diamantina; 19 - Divinópolis; 20 Formiga; 21 - Frutal; 22 - Governador Valadares; 23 - Grão-Mogol; 24 - Guanhães; 25 - Ipatinga; 26 - Itabira; 27 - Itaguara; 28 - Itajubá; 29 - Ituiutaba; 30 - Janaúba; 31 - Januária; 32 - Juiz de Fora; 33 - Lavras; 34 - Manhuaçu; 35 - Mantena; 36 Montes Claros; 37 - Muriaé; 38 - Nanuque; 39 - Oliveira; 40 - Ouro Preto; 41 - Pará de Minas; 42 - Paracatu; 43 - Passos; 44 - Patos de Minas; 45 - Patrocínio; 46 - Peçanha; 47 - Pedra Azul; 48 - Pirapora; 49 - Pium-í; 50 - Poços de Caldas; 51 - Ponte Nova; 52 - Pouso Alegre; 53 - Salinas; 54 - Santa Rita do Sapucaí; 55 - São João Del-Rei; 56 - São Lourenço; 57 - São Sebastião do Paraíso; 58 - Sete Lagoas; 59 - Teófilo Otôni; 60 - Três Marias; 61 - Ubá; 62 - Uberaba; 63 - Uberlândia; 64 Unaí; 65 - Varginha; 66 - Viçosa. 
A análise fatorial multivariada torna possível examinar minuciosamente as variáveis que mais se relacionam e construir agrupamentos como fatores, ou seja, as variáveis elencadas para este estudo são dados quantitativos discretos que tem por meta trazer uma maior ponderação sobre as circunstancias territoriais do envolvimento científico. Assim, os dados são intensificados, isto é, aumentam-se as suas características representativas para melhor reconhecer as diferenças que causam maior envolvimento científico ou tecnológico de modo multidimensional. Com o uso da análise fatorial e com o método dos componentes principais, estimaram-se diferentes equações que permitiram quantificar o Indicador de Envolvimento Científico, e a partir deste ponto, determinar suas medidas expansivas e classificá-los.

Os passos para a construção do indicador desta proposta, seguem as determinações a abaixo:

1 - Estimar as cargas fatoriais e os fatores comuns;

2 - Estimar os escores fatoriais;

3 - Analisar o ajuste dos dados no modelo, por intermédio do teste de Kaiser-Meyer-Olkin $(K M O)$;

4 - Formatar o Indicador de Envolvimento Científico.

\subsection{Método dos componentes principais}

Os métodos dos componentes principais são usuais na análise fatorial quando o objetivo é decompor em fatias (fatores) todas as informações inseridas no modelo, que possibilita analisar quanto cada fator colabora com a explicação da variância total dos dados amostrais. Esta conjunção linear é observada entre as variáveis e os fatores, como exemplifica a Equação 1.

Equação 1:

Sendo:

$$
X_{i}=A_{i l} F_{1}+A_{i l} F_{2}+A_{i l} F_{3} \ldots A_{i k} F_{k}+E_{i}
$$

$A_{i k}=$ Cargas fatoriais, usadas para conjecturar de modo linear os fatores comuns

$F_{k}=$ Fatores Comuns

$E_{i}=$ Fator de erro

A veemência em que se relacionam as variáveis originais e os fatores tem sua demonstração pelas cargas fatoriais, deste modo, o quadrado do resultado auferido municiona o potencial de explicação que a variação em uma variável tem sobre o fator. Os fatores que não tem relação entre si são considerados como fatores comuns. A parcela das informações elencadas que não são explicadas por nenhuma das variáveis inseridas no modelo, são enquadrados no erro (BEZERRA, 2007; EBERHARDT, 2013).

Ao intensificar o coeficiente dos escores $\left(\boldsymbol{\omega}_{\boldsymbol{j i}}\right)$ pelas variáveis originais, tem-se o valor dos escores finais. Assim, conforme a linguagem da matemática algébrica, os escores fatoriais são expressos por:

Equação 2:

$$
F_{j}=\omega_{j 1} X_{1}+\omega_{j 2} X_{2}+\omega_{j 3} X_{3}+\cdots+\omega_{j p} X_{p}, F_{j}=\sum_{i=1}^{i} \omega_{j i} X_{i}
$$

A Equação 2 enfatiza que $\boldsymbol{F}_{\boldsymbol{j}}$ é composto por fatores comuns que não são relacionados, e os valores contidos em $\boldsymbol{\omega}_{\boldsymbol{j} \boldsymbol{i}}$ são os coeficientes dos escores dos fatores, e $\boldsymbol{X}_{\boldsymbol{i}}$ refere-se as variáveis e $p$ é o número de variáveis existentes no modelo.

Neste trabalho, também foi realizado o teste de Kaiser-Meyser-Olkin (KMO), que é importante para examinar se a composição das variáveis inseridas no modelo possui uma estrutura adequada, além de verificar qual o nível de correlação entre todas as variáveis (conjuntamente) e cada variável (parcialmente) (REIS, 1997). Os resultados encontrados por intermédio do KMO são resultados da Equação 3.

Equação 3:

$$
K M O=\frac{\sum_{i=1}^{P} \sum_{i=1}^{P} r_{i j}^{2}}{\sum_{i=1}^{P} \sum_{i=1}^{P} r_{i j}^{2}+\sum_{i=1}^{P} X_{i}^{2} \sum_{i=1}^{P} a_{i j}^{2}}
$$

Para testar as pré-condições metodológicas da análise fatorial, além do KMO, utiliza-se o Barlett Teste Sphericity (BTS), cujo objetivo é verificar se a matriz de correlação é uma matriz identidade, isto é, 
se a diagonal é igual a 1 e todas as outras informações contidas na matriz são iguais a zero, o que acarretaria em ausência de correlação entre as variáveis.

Depois de presumir as cargas fatoriais e os escores fatoriais, usa-se Equação 4 para elencar uma média ponderada para cada unidade de amostra (microrregião), também conhecido como Indicador Bruto.

Equação 4:

Em que:

$$
I B=\frac{\sum_{i=1}\left(w_{i} F_{i}\right)}{\sum_{i=1} w_{i}}
$$

$\mathrm{IB}=$ Indicador Bruto;

$\mathrm{W}_{\mathrm{i}}=$ proporção da variância explicada por cada fator;

$\mathrm{F}_{\mathrm{i}}=$ escores fatoriais.

Para mensurar IECT, em que cada unidade de análise (microrregião) com maior indicador irá receber o valor de 1,00. A microrregião que obter o menor indicador receberá o valor de 0,00. Portanto, a equação que irá dar formato ao IECT, será:

Equação 5:

E em sua constituição:

$$
I E C T=\frac{X-I B_{\min }}{I B_{\max }-I B_{\min }}
$$

$\mathrm{X}=$ Valor do Indicador bruto da unidade de análise (microrregião);

$I B_{\min }=$ Valor da microrregião de menor Indicador Bruto;

$I B_{\max }=$ Valor da microrregião de maior Indicador Bruto.

Como objetivo fim é organizar o perfil de envolvimento científico e tecnológico em estágios, sejam considerados; avançado, transitório ou tardio.

Tabela 1

Classificação do IECT para as microrregiões de Minas Gerais

\begin{tabular}{lcc}
\hline Estágio & Limite Inferior & Limite Superior \\
\hline IECT - Avançado & 0,600 & 1,000 \\
IECT - Transitório & 0,200 & 0,600 \\
IECT - Tardio & 0,00 & 0,200 \\
\hline
\end{tabular}

Fonte: Elaborado pelo autor (2018).

Os estágios estão classificados na Tabela 1 com o intuito de compreender e mencionar a classificação das microrregiões de Minas Gerais. O local com o IECT abaixo da média é denominado IECT - Tardio, o local com o IECT acima da média é denominado IECT - Transitório, e o local com o IECT acima de dois desvios-padrão foi denominado como IECT - Avançado.

\subsection{Caracterização das variáveis que constituem o IECT}

Conforme foi detalhado anteriormente neste texto, o tema desenvolvimento científico é correlacionado com diversas complexidades, sejam elas de profundidade teórica, passando pelas características locais desenvolvidas por cada sociedade, chegando até a heterogeneidade que envolve a ciência econômica. Tais características são as mais plurais e diversas que enredam a mensuração local das capacidades científicas e tecnológicas em diferentes lugares.

Como o objetivo de observar diferentes estágios do envolvimento local com a ciência e a tecnologia, fez-se necessário selecionar informações mais recentes disponíveis para compor o IECT. As variáveis descritas nesta análise estão acompanhadas de uma breve descrição, período, e tipo de variável, encontram-se na Tabela 2. 
Tabela 2

Variáveis que compõem o IECT

\begin{tabular}{|c|c|c|c|c|}
\hline Variável & Descrição & Período & Fonte & $\begin{array}{l}\text { Tipo de } \\
\text { Variável }\end{array}$ \\
\hline População & $\begin{array}{l}\text { Quantidade de } \\
\text { Residentes }^{2}\end{array}$ & 2010 & IBGE & Demográfica \\
\hline População Urbana & $\begin{array}{l}\text { População Urbana a } \\
\text { cada } 1.000 \text { habitantes }^{3}\end{array}$ & 2010 & IBGE & Demográfica \\
\hline $\begin{array}{l}\text { Distância da } \\
\text { Capital }\end{array}$ & $\begin{array}{c}\text { Km de distância da } \\
\text { capital }^{4}\end{array}$ & Indeterminado & DEER/MG & Geográfica \\
\hline Emprego & $\begin{array}{c}\text { Número de empregados, } \\
\text { indústria }\end{array}$ & 2016 & RAIS & Social \\
\hline $\begin{array}{l}\text { Estabelecimentos } \\
\text { Industriais }\end{array}$ & $\begin{array}{l}\text { Quantidade de } \\
\text { estabelecimentos }\end{array}$ & 2016 & RAIS & Social \\
\hline $\begin{array}{l}\text { Estabelecimentos } \\
\text { de Ensino } \\
\text { Superior }\end{array}$ & $\begin{array}{l}\text { Graduação e Pós- } \\
\text { Graduação }\end{array}$ & 2016 & RAIS & Social \\
\hline $\begin{array}{l}\text { Estabelecimentos } \\
\text { de Ensino } \\
\text { Superior }\end{array}$ & $\begin{array}{c}\text { Pós-Graduação e } \\
\text { Extensão }\end{array}$ & 2016 & RAIS & Social \\
\hline $\begin{array}{l}\text { Professores - } \\
\text { Ensino Superior }\end{array}$ & $\begin{array}{l}\text { Número de professores } \\
\text { vinculados à instituições } \\
\text { de ensino superior, em } \\
\text { nível de Graduação }\end{array}$ & 2016 & RAIS & Social \\
\hline $\begin{array}{l}\text { Professores - } \\
\text { Ensino Superior }\end{array}$ & $\begin{array}{l}\text { Número de professores } \\
\text { vinculados à instituições } \\
\text { de ensino superior, em } \\
\text { nível de Pós-graduação }\end{array}$ & 2016 & RAIS & Social \\
\hline $\begin{array}{l}\text { Professores - } \\
\text { Ensino Superior }\end{array}$ & $\begin{array}{c}\text { Número de professores } \\
\text { vinculados à instituições } \\
\text { de ensino superior, em } \\
\text { Extensão }\end{array}$ & 2016 & RAIS & Social \\
\hline $\begin{array}{l}\text { Professores - } \\
\text { Ensino Técnico }\end{array}$ & $\begin{array}{l}\text { Número de Professores } \\
\text { vinculados à instituições } \\
\text { de ensino técnico }\end{array}$ & 2016 & RAIS & Social \\
\hline $\begin{array}{l}\text { Professores - } \\
\text { Ensino } \\
\text { Tecnológico }\end{array}$ & $\begin{array}{l}\text { Número de Professores } \\
\text { vinculados à instituições } \\
\text { se ensino tecnológico }\end{array}$ & 2016 & RAIS & Social \\
\hline $\begin{array}{l}\text { Trabalhadores } \\
\text { qualificados }\end{array}$ & Graduação & 2016 & RAIS & Social \\
\hline Trabalhadores & Mestrado & 2016 & RAIS & Social \\
\hline
\end{tabular}

${ }^{2}$ Com o objetivo de preservar as microrregiões que possuem populações mais numerosas, e consequentemente maior produção e despesas públicas, as variáveis desta pesquisa foram alteradas para que não haja o viés do efeito escala. Ou seja, todas as informações foram dispostas na mesma grandeza, normalizadas pela seguinte equação:

$\mathrm{z}=\left(\mathrm{x} \_(\mathrm{i})-\mathrm{x} \overline{)} / \sigma\right.$

Em que: $\mathrm{z}=$ normalização; $\mathrm{x} \_\mathrm{i}=$ variável observada; $\mathrm{x}^{-}=$variável média; $\sigma=$ desvio padrão.

${ }^{3}$ Referente à: (População Urbana / População Total). 1000

${ }^{4}$ Para esta variável, foi criado um índice para a importância de proximidade. Ou seja, aquelas microrregiões que estão próximas (em Quilômetros) à microrregião de Belo Horizonte, assumiram valores próximos a 100, e aquelas microrregiões mais distantes de Belo Horizonte, assumiram valores próximos a 0. Deste modo, pode-se dar peso ao fator distância da microrregião que comporta a Capital de Minas Gerais. 


\begin{tabular}{lcccc}
$\begin{array}{l}\text { Trabalhadores } \\
\text { qualificados }\end{array}$ & Doutorado & 2016 & RAIS & Social \\
Pesquisadores & $\begin{array}{c}\text { Pesquisadores } \\
\text { Policientíficos }\end{array}$ & 2016 & RAIS & Social \\
\hline
\end{tabular}

A tabela 2 continua na próxima página.

Continuação da tabela 2.

\begin{tabular}{lcccc}
\hline $\begin{array}{l}\text { Salário Médio } \\
\text { Industrial }\end{array}$ & $\begin{array}{c}\text { Média Salarial dos } \\
\text { trabalhadores da } \\
\text { Indústria }\end{array}$ & 2016 & RAIS & Econômica \\
$\begin{array}{l}\text { Número de } \\
\text { Patentes }\end{array}$ & $\begin{array}{c}\text { Quantidade de patentes } \\
\text { registradas localmente }\end{array}$ & 2000 à 2012 & INPI & Econômica \\
PIB per capta & $\begin{array}{c}\text { Produção Interna Bruta } \\
\text { per capta }\end{array}$ & 2015 & $\begin{array}{c}\text { SIDRA- } \\
\text { IBGE }\end{array}$ & Econômica \\
VAB & Valor Adicionado Bruto & 2015 & $\begin{array}{c}\text { SIDRA- } \\
\text { IBGE }\end{array}$ & Econômica \\
\hline
\end{tabular}

Fonte: Dados da pesquisa (2017)

É importante mencionar que a construção do IECT proposto nesta pesquisa, envolve as variáveis disponíveis mais próximas do ano de 2018. As variáveis dispostas em anos anteriores, são as mais recentes e, servem como proxy para esta análise.

A taxa de urbanização refere-se à proporção da população que ocupam moradias em área urbana em relação à população geral. O número de professores (graduação, pós-graduação, extensão), corresponde à soma de todos estes profissionais ocupando postos de trabalho formal, intensificado a cada 100.000 habitantes. O mesmo foi feito para o número de pesquisadores.

\footnotetext{
5 Segundo a Classificação Brasileira de Ocupações - CBO, os pesquisadores policientíficos são aqueles que desenvolvem pesquisas científicas em ciências naturais e exatas tais como, computação e informática, meio ambiente, química, física e matemática, coletando, analisando e tratando dados físicos, químicos, biológicos, culturais e de fontes secundárias. Criam metodologias, técnicas, equipamentos e ferramentas para pesquisa com a realização de experimentos e a construção de modelos e teorias. Elaboram projetos e coordenam atividades de pesquisa, formam recursos humanos, disseminam conhecimentos científicos. Podem prestar serviços de consultoria, realizar avaliações em P\&D, bem como dar aulas.

${ }^{6}$ Considerado a massa salarial (em salários mínimos) disponível nos microdados da RAIS, convertidos e ajustados para Reais de 2018.
} 


\section{RESULTADOS E DISCUSSÕES}

Dentre as informações utilizadas nesta análise, extraíram-se dois fatores com raiz característica maior que a unidade, que sintetizam as dezessete variáveis usadas a princípio, explicando a variância de todas as variáveis empregadas em $79,55 \%$. Para melhor ajustamento das variáveis usadas no modelo, utilizou-se os dados pelo método varimax. A Tabela 3 destaca os dados rotacionados além de assinalar que em 7 fatores (dos dezessete utilizados) pode-se explicar 97,74\% da variância total das variáveis escolhidas.

Tabela 3

Raiz característica, percentual explicativo por fator, e variância acumulada

\begin{tabular}{cccc}
\hline Fator & $\begin{array}{c}\text { Raiz } \\
\text { característica }\end{array}$ & $\begin{array}{c}\text { Variância explicada pelo } \\
\text { fator }(\boldsymbol{\%})\end{array}$ & $\begin{array}{c}\text { Variância acumulada } \\
(\boldsymbol{\%})\end{array}$ \\
\hline F1 & $\mathbf{1 1 , 7 0}$ & $\mathbf{6 8 , 8 3}$ & $\mathbf{6 8 , 8 3}$ \\
F2 & $\mathbf{1 , 8 2}$ & $\mathbf{1 0 , 7 3}$ & $\mathbf{7 9 , 5 5}$ \\
F3 & 0,89 & 5,24 & 84,79 \\
F4 & 0,81 & 4,75 & 89,54 \\
F5 & 0,70 & 4,12 & 93,66 \\
F6 & 0,45 & 2,64 & 96,30 \\
F7 & 0,25 & 1,44 & 97,75 \\
\hline
\end{tabular}

Fonte: Resultados da pesquisa

O teste de Bartlettfoi significativo (exposto na tabela 4), ou seja, rejeita-se a hipótese nula que a matriz de correlação seja uma matriz identidade. O teste de Kaiser-Meyer-Olkin(KMO), enfatiza que o ajuste do modelo emprego é apropriado, com o valor de 0,918.

Tabela 4

Teste de Kaiser-Meyer-Olkine de Bartlett

\section{Teste KMO e teste de Bartlett}

Medida Kaiser-Meyer-Olkin de adequação de amostragem

Teste de esfericidade de Bartlett
Aprox. Qui-

,918

2625,739

df

Sig.
136

, 000

Fonte: Resultados da pesquisa

A Tabela 5 traz a matriz de correlação entre as principais variáveis do modelo, Trabalhadores Doutores, Pesquisadores Policientíficos, e Registro Local de Patentes, ou seja, destaca as informais mais impactantes no envolvimento científico local.

Tabela 5

Matriz de correlação dentre as principais variáveis

\begin{tabular}{lccc}
\hline Variáveis & $\begin{array}{c}\text { Trab. } \\
\text { Doutores }\end{array}$ & $\begin{array}{c}\text { Pesq. } \\
\text { Policientíficos }\end{array}$ & $\begin{array}{c}\text { Reg. Local de } \\
\text { Patente }\end{array}$ \\
\hline População Total & 0,97 & 0,98 & 0,98 \\
Profs. Pós-Graduação & 0,97 & 0,98 & 0,99 \\
Profs. Tecnológicos & 0,83 & 0,85 & 0,86 \\
Trabalhadores Mestres & 0,98 & 0,99 & 1,00 \\
Trabalhadores Doutores & 1,00 & 0,97 & 0,98 \\
Pesquisadores Policientíficos & 0,97 & 1,00 & 1,00 \\
Empregos na Indústria & 0,94 & 0,94 & 0,95
\end{tabular}


Reg. Local de Patente

Trabalhadores com Ensino Superior

VAB Indústria (mil reais)

Estabelecimentos de Pós-Graduação e

Extensão

$\begin{array}{lll}0,98 & 1,00 & 1,00 \\ 0,98 & 0,99 & 1,00 \\ 0,95 & 0,96 & 0,96 \\ 0,97 & 0,99 & 0,99\end{array}$

0,96

0,99

Fonte: Resultados da pesquisa.

É importante mencionar que as variáveis de menor correlação com as variáveis de interesse foram: Salário médio da Indústria, PIB per capita, Importância de distância da microrregião de Belo Horizonte, e Proporção da população urbana. Neste sentido, esta pesquisa destaca que o envolvimento com atividades de ciência e tecnologia tem pouca associação correspondente com as variáveis acima destacadas.

\subsection{Classificação do Envolvimento Científico e nas Microrregiões de Minas Gerais}

A partir do método de análise proposto nesta pesquisa, encontrou-se somente uma microrregião com parâmetros de envolvimento científico e tecnológico avançado (com valores do IECT entre 0.60 e 1.00), em estágio transitório foram 15 microrregiões (apresentando resultados do IECT entre 0.20 e 0.60 ). A partir da Figura 2, pode-se visualizar que a distribuição dos estágios "transitório" e "avançado" não ocorrem em todas as mesorregiões, mas somente em 6 das 11 consideradas nesta análise.

\section{Figura 2}

Os estágios $^{7}$ de Envolvimento Científico e Tecnológico nas Microrregiões de Minas Gerais ${ }^{8}$

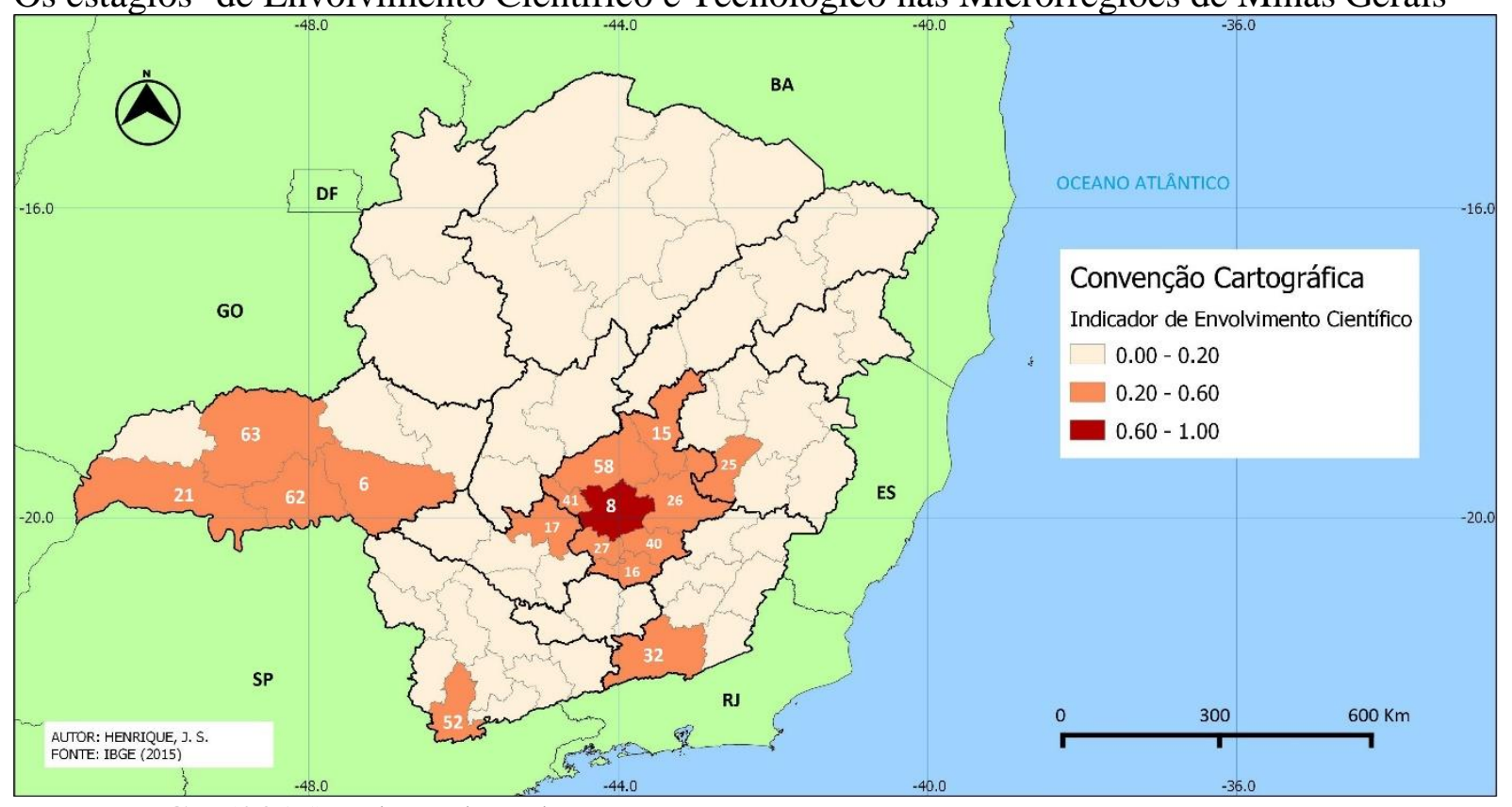

Fonte: IBGE (2015), adaptado pelo autor.

A partir dos resultados apresentados na Figura 2, torna-se possível destacar que a microrregião que auferiu o maior resultado no IECT foi a de Belo Horizonte ${ }^{9}$, ou seja, esta microrregião além de possuir maior envolvimento com a ciência, também apresentou os maiores valores para a grande maioria das variáveis que foram inseridas neste indicador. Dentre as variáveis que compõem o IECT, nota-se que

\footnotetext{
${ }^{7}$ Considerando IEC - Avançado: 0.60 - 1.00; IEC - Transitório: 0.20 - 0.60; IEC - Tardio 0.00 - 0.20

${ }^{8}$ Para facilitar a interpretação e a leitura dos resultados, nesta figura também há o destaque para as mesorregiões de Minas Gerais, embora os resultados são referentes às microrregiões, que são: Campo das Vertentes; Central Mineira; Jequitinhonha; Metropolitana de Belo Horizonte; Noroeste de Minas; Norte de Minas; Oeste de Minas; Sul/Sudoeste de Minas; Triângulo Mineiro/Alto Paranaíba; Vale do Mucuri; Vale do Rio Doce; Zona da Mata.

${ }^{9}$ Identificada como microrregião número 8 na Figura 2.
} 
a maior importância para a composição dos resultados encontrados em Belo Horizonte, está principalmente em registro local de patentes; estabelecimentos de graduação, pós-graduação, e extensão, bem como em número de professores vinculados à estas instituições; professores de ensino tecnológico, trabalhadores formais com doutorado, e pesquisadores policientíficos. Deste modo, pode-se entender que a microrregião de Belo Horizonte, está polarizando de modo integral o envolvimento com a ciência e também com o desenvolvimento tecnológico.

Dentro da mesorregião Metropolitana ${ }^{10}$, percebe-se claramente um efeito transbordamento do envolvimento científico ou tecnológico na região, ou seja, as microrregiões que possuem proximidade geográfica com a microrregião de Belo Horizonte, são caracterizadas também por maior envolvimento científico. Característica esta que da mesma forma se expande para algumas microrregiões próximas à mesorregião metropolitana, que é o caso da microrregião de Divinópolis ${ }^{11}$ (localizada na mesorregião Oeste de Minas), e a microrregião de Ipatinga ${ }^{12}$ (localizada na mesorregião Vale do Rio Doce. Estas microrregiões formam a principal aglomeração com localidades com IECT com resultados avançados e transitórios.

O segundo agrupamento de microrregiões com IECT transitório encontra-se na mesorregião Triângulo Mineiro e Alto Parnaíba. Os resultados obtidos por esta análise mencionaram as microrregiões de Uberlândia e Uberaba (respectivamente identificadas na Figura 2 como microrregiões 63 e 62), apresentaram os maiores da microrregião com registro de patente local, bem como com o número de trabalhadores doutores, igualmente com os valores de profissionais policientíficos, e em estabelecimentos de graduação e pós-graduação. As microrregiões de Frutal e Araxá (respectivamente representados por 21 e 6) também apresentam valores muito próximos aos resultados auferidos pelas demais microrregiões de classificação transitória. Isto posto, tem-se que 4 das 7 microrregiões que constituem este aglomerado local.

Ainda presente nos resultados desta análise, as microrregiões de Pouso Alegre (na mesorregião Sul e Sudoeste de Minas), e Juiz de Fora (na mesorregião Zona da Mata) ${ }^{13}$, auferiram valores do IECT de classificação transitória, ou seja, além de não apresentaram nenhum padrão de concentração espacial, também não se destacaram por transbordamento do seu envolvimento científico com as microrregiões vizinhas. Deve-se destacar que estas microrregiões fazem divisa com o estado de São Paulo e Rio de Janeiro, e que possivelmente possam estar espacialmente coligadas com pólos regionais além das divisas do estado de Minas Gerais.

\footnotetext{
${ }^{10}$ Regiões desta análise: 15 - Conceição do Mato Dentro; 16 - Conselheiro Lafaiete; 26 - Itabira; 27 - Itaguara; 40 - Ouro Preto; 41 - Pará de Minas; 58 - Sete Lagoas.

${ }^{11}$ Microrregião representada pelo número 17.

12 Microrregião representada pelo número 25.

${ }^{13}$ Microrregiões respectivamente representadas pelos números 52 e 32.
} 


\section{CONSIDERAÇÕES FINAIS}

O propósito do presente trabalho foi de contribuir empiricamente para a análise do sistema regional de inovação de Minas Gerais. Ao considerar as 66 microrregiões mineiras. A análise que permeia a estrutura do envolvimento científico e tecnológico nestas microrregiões é fundamentada por variáveis proxys, o conjunto destas variáveis tem por objetivo construir indicações e aproximações que possibilitam a avaliação e classificação do envolvimento com a ciência e tecnologia, em diferentes escalas. Partindo da compreensão que o Desenvolvimento regional, altamente coligado com fatores da economia regional, está envolto com a capacidade de produção interna, que por sua vez possui uma relação estrita com atividades produtivas de a inovação, ciência e tecnologia. Neste sentido, o referencial teórico norteador deste trabalho nos remete que as características locais fomentam a aglomeração industrial, além da produção de profissionais de alta qualificação, bem como a presença de trabalho qualificado no mercado de trabalho local, trazem vantagens para um ambiente propício ao desenvolvimento dos processos inovativos.

Além das vantagens da aglomeração local que tendem a configurar estruturas de suporte à ciência e a tecnologia, as relações de proximidade geográfica com as regiões de aglomeração respondem como possibilidades de compartilhamento, em termos de financiamentos, agentes especializados, mão de obra qualificada, além do transbordo do conhecimento que, ao longo do tempo, tende a transpassar as fronteiras locais e dispersando-se em seu entorno. Com este cenário, há também a formação do conhecimento tácito, que é compartilhado entre a interação entre os agentes envolvidos no sistema de inovação, característica essa que obstaculiza para a transferência em longas distâncias.

Através do método de Análise Fatorial dos Componentes Principais, foi elaborado o Indicador de Envolvimento Científico e Tecnológico para as microrregiões do estado, que por sua vez possibilita identificar, e comparar regionalmente os estágios das estruturas que circundam as atividades da ciência e tecnologia, bem como classifica-las em avançadas, transitórias ou retardatárias.

Os resultados enfatizaram dois grandes grupos em faze avançada e transitória. O principal resultado está na microrregião de Belo Horizonte, que por sua vez tem os maiores resultados obtidos nesta análise, bem como nas principais proxys inseridas na formação do IECT deste trabalho.

O efeito transbordamento é uma característica do envolvimento científico e tecnológico em Minas Gerais, tendo que o principal agrupamento de microrregiões em estágio transitório é formado pelas microrregiões da região metropolitana de Belo Horizonte, e algumas adjacentes, mas com muita proximidade geográfica à capital mineira.

O segundo agrupamento é formado na mesorregião Triângulo Mineiro e Alto Parnaíba, com as microrregiões de Uberlândia, Uberaba, Frutal e Araxá. Este agrupamento traz resultados similares aos encontrados na Região Metropolitana de Belo Horizonte, em que as principais microrregiões desta análise (Uberlândia e Uberaba) trazem os principais resultados, e consequentemente, o seu efeito transbordamento excede as fronteiras locais, transmitindo-o para as microrregiões vizinhas. É importante mencionar que nenhuma destas microrregiões em destaque resultaram valores próximos à valores que as caracterizem próximas a região mais avançada do estado, sendo todas elas classificadas como transitórias.

A partir dos resultados encontrados nesta pesquisa, fica evidente que ao considerar todas as microrregiões de Minas Gerais, tendo o próprio estado mineiro como referência, ficam mais evidentes as desigualdades locais em um quadro estadual. Isto é, em termos da concentração de estruturas envoltas com a ciência e tecnologia, esta análise expõe uma grande concentração na capital e seu entorno, além de destacar que as demais regiões mineiras não apresentam um número mínimo de estrutura de apoio ao desenvolvimento da ciência e tecnologia, ou seja são regiões retardatárias. As regiões periféricas do estado, classificadas como IECT-retardatário, são carentes em capacidades inovativas, apresentando um forte indício que há dificuldades para alcançar as regiões mais desenvolvidas do estado. 


\section{REFERÊNCIAS}

ARROW, K. J. The economic implications of learning by doing. Review of Economic Studies,v. 29, p. 155-172, 1962.

ASHEIM, B. Industrial Districts as "learning regions": condition for prosperity? Em:IGU Commission on Interdependent and Uneven Development: global-local perspectives. Seoul, p.7-11 ago. 1995,Seoul: Step Group.

BEZERRA, F. A. Análise fatorial. In: CORRAR, L. J.; PAULO, E.; DIAS FILHO, J. M. (Orgs). Análise Multivariada para cursos de Administração, Ciências Contábeis e Economia. São Paulo: Atlas, 2007.

BITTENCOURT, P.; CÁRIO, S. Sistemas de Inovação: das raízes no século XIX à análise global contemporânea. Em: RAPINI, M.; SILVA, L.; ALBUQUERQUE, E. (Org.). Economia da Ciência, Tecnologia e Inovação: fundamentos teóricos e economia global.1.ed. Curitiba: Prismas, 2017. cap. 9, p.331-370.

DOSI, G. The nature of the innovative process. Em: DOSI, G. (Ed.).Technical Change and Economic Theory. Londres: Pinter, 1988. cap.10, p.221- 238.

EBERHARDT, P.H. C. Estágios de desenvolvimento econômico regional no Sul do Brasil. Dissertação (Mestrado).2013. 102 f.-. Centro de Ciências Sociais Aplicadas,Universidade Estadual do Oeste do Paraná. Campus de Toledo, Toledo, 2013.

FREEMAN, C. The national system of innovation in historical perspective. Cambridge JournalofEconomics, v.19 p.5-24. 1995.

FROEHLICH, C.; NEUMANN, L. Desenvolvimento humano em municípios gaúchos: um estudo através da análise fatorial. Perspectivas contemporâneas. v. 2, nº 2, p. 79-100. 2007.

GARCIA, R. Geografia da Inovação. Em: RAPINI, M.; SILVA, L.; ALBUQUERQUE, E. (Org.). Economia da Ciência, Tecnologia e Inovação: fundamentos teóricos e economia global. 1.ed. Curitiba: Prismas, 2017.cap. 7, p.241-286.

GUALDA, N. L. P. IDR - Proposta Metodológica. Texto para Discussão. Programa de Mestrado em Economia - PME. Universidade Estadual de Maringá, 1995.

JACOBS, J. The Economy of Cities. New York: Random House Inc, 1969.

LUNDVALL, B. (Ed.) National Systems of Innovation: Towards a Theory of Innovation and Interactive Learning. Londres: Pinter, 1992.

Nelson, R. e Rosenberg, N. Technical Innovation and National Systems. Em: NELSON, R. (Ed.). National Innovation Systems. New York: Oxford University Press, 1993. cap.1, p.3-21

NELSON, R.; WINTER, S. G. In Search of Useful Theory of Innovation. Research Policy. V.6, p. 3676. 1977.

NELSON, R.; WINTER, S. G. An Evolutionary Theory of Economic Change. Cambridge: Harvard University, 1982. 
PEROBELlI, F. S.; OLIVEIRA, A. F.; NOVY, L. G. G; FERREIRA, M. V. Planejamento regional e potenciais de desenvolvimento dos municípios de Minas Gerais na região em torno de Juiz de Fora: uma aplicação da análise fatorial. Nova Economia. v.9, n.1, p. 121-150. 1999.

PRATES RODRIGUES, M. C. Potencial de desenvolvimento dos municípios fluminenses: uma metodologia alternativa ao IQM, com base na análise fatorial exploratória e na análise de clusters. Caderno de Pesquisas em Administração. v. 9, n.1, p.75-89. 2002.

REIS, E. Estatística multivariada aplicada. Editora: Silabo: Lisboa. 1997.

SANTOS, U. P.; CALIARI, T. Distribuição Espacial das Estruturas de Apoio às Atividades Tecnológicas no Brasil: uma análise multivariada para as cinquenta maiores microrregiões do país. EconomiA. v.13, set. 2012.

SCHUMPETER, J. A Teoria do Desenvolvimento Econômico.São Paulo: Nova Cultural, 1985 [1911].

SZAPIRO, M.; MATTOS, M.; CASSIOLATO, J. Sistemas de Inovação e Desenvolvimento. Em: RAPINI, M.; SILVA, L.; ALBUQUERQUE, E. (Org.). Economia da Ciência, Tecnologia e Inovação: fundamentos teóricos e economia global. 1.ed. Curitiba: Prismas, 2017. cap.10, p371-412. 
Tabela 7

Índice de Envolvimento Científico para as microrregiões de Minas Gerais

\begin{tabular}{cccccc}
\hline Microrregião & IECT & Microrregião & IECT & Microrregião & IECT \\
\hline Aimorés & 0,08 & Grão-Mogol & 0,00 & Peçanha & 0,02 \\
Alfenas & 0,16 & Guanhães & 0,08 & Pedra Azul & 0,06 \\
Almenara & 0,04 & Ipatinga & 0,30 & Pirapora & 0,19 \\
Andrelândia & 0,11 & Itabira & 0,29 & Pium-í & 0,17 \\
Araçuaí & 0,00 & Itaguara & 0,22 & Poços de Caldas & 0,20 \\
Araxá & 0,31 & Itajubá & 0,16 & Ponte Nova & 0,12 \\
Barbacena & 0,17 & Ituiutaba & 0,18 & Pouso Alegre & 0,30 \\
Belo Horizonte & 1,00 & Janaúba & 0,06 & Salinas & 0,02 \\
Bocaiúva & 0,10 & Januária & 0,01 & Santa Rita do Sapucaí & 0,15 \\
Bom Despacho & 0,20 & Juiz de Fora & 0,25 & São João Del-Rei & 0,18 \\
Campo Belo & 0,14 & Lavras & 0,20 & São Lourenço & 0,14 \\
Capelinha & 0,04 & Manhuaçu & 0,10 & São Sebastião do Paraíso & 0,16 \\
Caratinga & 0,09 & Mantena & 0,07 & Sete Lagoas & 0,25 \\
Cataguases & 0,17 & Montes Claros & 0,17 & Teófilo Otoni & 0,07 \\
Conceição do Mato Dentro & 0,23 & Muriaé & 0,12 & Três Marias & 0,20 \\
Conselheiro Lafaiete & 0,31 & Nanuque & 0,07 & Ubá & 0,18 \\
Curvelo & 0,14 & Oliveira & 0,15 & Uberaba & 0,31 \\
Diamantina & 0,12 & Ouro Preto & 0,38 & Uberlândia & 0,32 \\
Divinópolis & 0,26 & Pará de Minas & 0,21 & Unaí & 0,13 \\
Formiga & 0,19 & Paracatu & 0,20 & Varginha & 0,20 \\
Frutal & 0,21 & Patos de Minas & 0,19 & Viçosa & 0,10 \\
Governador Valadares & 0,17 & Patrocínio & 0,16 & & \\
\hline
\end{tabular}

Fonte: Resultados da pesquisa. 